\title{
BIOSIMILAR CURRENT STATUS IN INDIA
}

\author{
RAJU KAMARAJ, MANOHARAN MANJU*
}

School of Public Health, SRM University, Kattankulathur - 603 203, Kanchipuram, Tamil Nadu, India. Email: monishakamaraj@gmail.com

Received: 22 August 2016, Revised and Accepted: 21 September 2016

\section{ABSTRACT}

Biosimilars are biological products that are the replica of their innovator biopharmaceuticals. These are developed after patent expiration of innovator biopharmaceuticals and are submitted for separate marketing approval. In view of the structural and manufacturing complexities of biopharmaceuticals, biosimilars should not be considered as "biological generics." The objective of the article will address the current Indian scenario conducting the clinical trial biological and biosimilar product regulatory requirements for approval of biological and biosimilar product. The New India Guidelines “Draft Guidelines on Similar Biologics were announced in June 2012, by the department of biotechnology at Boston bio and available in India.

Keywords: Biosimilars, Biopharmaceutical, Innovator biopharmaceuticals.

(C) 2017 The Authors. Published by Innovare Academic Sciences Pvt Ltd. This is an open access article under the CC BY license (http://creativecommons. org/licenses/by/4. 0/) DOI: http://dx.doi.org/10.22159/ajpcr.2017.v10i7.14814

\section{INTRODUCTION}

A biosimilar is a biologic product that is similar, but not identical, to a reference product, and therefore, requires separate marketing approval on patent expiration of the reference product. Biosimilars are not generic versions of biologics [1]. The active ingredient in a generic small molecule drug is a single molecular structure and can readily be reproduced by chemical synthesis, but the active substance in a biologic product is a collection of large protein isoforms, thus making reproduction more complex [1,2]. "Biosimilar" is the term used in Europe and the U.S., "follow-on pharmaceuticals" in Japan, "subsequent entry biologics" in Canada, and "biocomparables" in Mexico. The original version of a biologic is referred to as the "originator," "innovator," "pioneer," or "reference" drug. A biologic drug, in general, is also referred to as a "biopharmaceutical," "bio drug," "biologic," or "biological."

\section{ORIGIN AND MANUFACTURING}

Biologics, whether reference or biosimilar, are produced with living cells through the use of biotechnology such as recombinant DNA technology, controlled gene expression, or antibody technologies [2,3]. Since biologics are made with cells in culture or whole organisms such as plants, animals, and microorganisms, they are inherently more variable than a small-molecule drug, such as aspirin, which is made by chemical synthesis $[2,4]$. Recombinant DNA technology refers to the process of using enzymes to cut and paste together DNA sequences of interest. The recombined DNA sequences can be placed into vectors that carry the DNA into a host cell, where the customized recombined DNA sequence can be copied or translate [5]. First-generation biologics were made directly from human and animal by-products such as human blood and porcine insulin. Second-generation biologics, however, are made by genetically engineering DNA within living organisms [6]. The benefit of this is notable in the example of immunological compatibility of genetically-engineered insulin versus porcine insulin, which can cause long-term immunological complications in some patients [4] The use of recombinant DNA technology to produce insulin depicts the manufacturing process for biologics.

Methods for manufacturing biologics are more complex than for small molecule drugs and involve several steps that are subject to variations affecting the biological and clinical properties of the product $[6,7]$. The sensitivity of biologics to manufacturing conditions is much greater than for chemical small molecules [8]. It is natural for proteins, once isolated from the host cells that produced them, to undergo certain chemical changes such as oxidation and deamidation. Subtle time- dependent changes in the shape of a protein can trigger undesirable effects such as protein insolubility, loss of biological function, or increased immunogenicity because of exposure of antigenic segments of the molecule that would usually be hidden from the immune system (Fig. 1).

The organisms from which the biosimilar and reference drug are produced may not be identical, and the production process of the reference drug remains confidential, even after the patent for the process expires [9]. As a result, the biosimilar and the reference biologic are not exact duplicates. Inherent variability also exists for the reference biologic and it must be noted that no batch of any reference product is identical to the previous one, as depicted by the difference between the middle molecule and one to its right. Note the different orientations of yellow lines each molecule, which represent minor alterations in post-translational modifications that should not affect clinical efficacy [10].

\section{HISTORY}

"Virus, therapeutic serum, toxin, vaccine, blood, blood component or derivative, allergenic product, or analogous products, applicable to the prevention treatment, or cure of disease or condition of human beings" are generally considered as biological products. They have been around for nearly two centuries, since the development of first commercial Blutserum therapy (serum therapy) by Behring and Kitasato. Behring's diphtheria serum therapy was first clinically tested in 1891 and by 1894, Faberwerke Hoechst launched the first biological product, antidiptheria serum (e.g., crude polyclonal antibody preparation), to combat a serious diphtheria epidemic in Europe).

One of the next advances in biological products was the introduction of heterologous insulin purified from pigs and cows, marketed as Iletin by Eli Lilly starting in 1923 as life-saving treatment for patients with type 1 diabetes mellitus. While additional animal serum-derived products were developed over the next half century, they increased the use of biologics therapy in incremental stages. The scenario changes last quarter of the $20^{\text {th }}$ century, with the advent of recombinant protein technology. Genentech led the path to production of recombinant therapeutic proteins in the late 1970s by cloning and expressing human somatostatin, insulin growth hormone, and human growth hormone (HGH) in Escherichia coli [11].

Recombinant human insulin, Humulin ${ }^{\mathrm{R}}$, the first recombinant human therapeutic protein was developed by Genentech and Eli Lilly, and the 


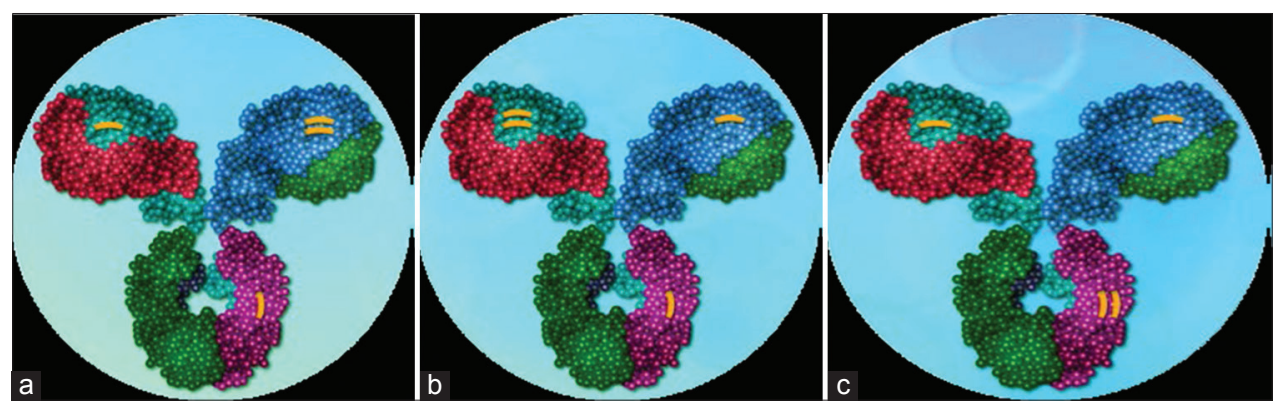

Fig. 1: Comparison between reference and biologic. (a) Biosimilar. (b and c) Biologic

first approved for sale in the US on October 30, 1982 [11]. The fully human protein, Humulin ${ }^{\mathrm{R}}$, helped to eliminate the issues with immune responses directed against heterologous insulin from livestock In the 27 years since Humulin was brought into the market, more than 165 biological products have been marketed for a broad array of therapeutic diseases. While few of these, such as a - antitrypsin and alpha-1-protenaise, are still purifies from human blood, the vast majority of biologics on the market today are from recombinant sources, requiring reliable, and consistent cell-based production platforms.

\section{CLASSIFICATION OF BIOLOGICAL PRODUCT}

Leader et al. have categorized a protein therapeutics which constitutes most of the biological products into four functional groups

- Protein therapeutics with enzymatic or regulatory activity (e.g., insulin growth hormone, factor $1 \mathrm{x}$ replacement therapies, and beta-gluco-cerebrosidase replacement therapy for Gaucher's diseases.

- Protein therapeutics with special targeting activity (e.g., monoclonal antibodies that bind specific therapeutic targets, such as the antitumor necrosis factor- $\alpha$ biologics.

- Vaccines (e.g., human papillomavirus (HPV) vaccine made using HPV major virus-like particles containing HPV major capsid protein L 1); and,

- Diagnostics (e.g., biomarkers such as glucagon, and imaging agents such as technetium-labeled antibodies)

\section{CURRENT SCENARIO}

\section{Contents}

\section{Biological products approved in India}

History of biological products in India: Recombinant hepatitis-B-surface antigen was the first indigenously developed and commercialized biopharmaceuticals in the year 1997. Several biopharmaceuticals have been indigenously developed and have received approval the last 13 years.

\section{Regulatory approval process for biological products}

Biological products are considered as NEW DRUGS as per the Indian "Drugs and Cosmetics Act." Products intended to be marketed in India are regulated by either drug Controller General of India or by DCGI or by DCGI and Department of Biotechnology (DBT). The history regulatory related to drug import, manufacture and sale are covered under the Drugs and Cosmetics Act of 1940 and Drugs and Cosmetics Rules of 1945. The Act's main objective is to ensure that available human drugs are safe efficacious and conform to prescribed quality standards, and marketed cosmetics are safe for use. CDSCO office along with the Indian Council of Medical Research have adopted international regulatory guidelines for biomedical research on human subjects in 2000 and Indian GCP guidelines were released by CDSCO office and Guidance on Common Technical document for the NDA application were other initiatives for streamlining the requirements for conducting clinical trial and new drug approval process in India.
Currently, clinical trials in India are regulated by Schedule Y of the Drug and Cosmetics Rules, 1945. During the amendment of drugs and cosmetics rules, 2005, the Schedule Y was extensively revised to bring the Indian regulations on par with internationally accepted definitions and procedures. Schedule Y defines the requirement and guidelines for and/or manufacture of new drugs for sale of clinical trials.

Clinical trial requirements for biosimilars or follow-on biologics The demonstration of bioequivalence of the generic non-biologic medicine with reference products usually appropriate and sufficient to infer therapeutic equivalence between the generic non-biologic medicine and the reference product. However, the approach established for generic non-biologic medicines is not suitable for development, evaluation and licensing of biosimilars (terminology used in Europe) or "follow-on biologics" (terminology used in the USA). To understand the clinical trial requirements, a brief outline of the dossier requirement for the approval for biosimilar with the reference from WHO guidelines is mentioned here. The office of DCGI has circulated draft biosimilar guidelines for India for comments from the stakeholders. The amount of data required evaluates the safety and efficacy of biosimilars is highly variable and is driven largely by the molecule evaluated and decided by the National Regulatory Authority, DCGI in India. Comparability to the innovator product is one of the most important requirements for a biosimilar product and includes an evaluation of physiochemical properties, biological preclinical and clinical comparability. The requirement for comparability data from a quality standpoint is significantly higher for biosimilar development compared to the development of a new and independent biological product. However, this extensive quality evaluation from a physiochemical, pharmaceutical, and biologic perspective reduces the amount of non-clinical and clinical data required for an approval of a biosimilar product. The requirement for biosimilar is organized and explained as shown in Table 1.

\section{Manufacturing and quality}

The administrative information summary should include details on the biosimilar product, its substance, raw materials, and manufacturing process. Differences with relevant attributes of the reference medicinal product should also be included. Any other changes introduced during the development which could affect the comparability should be highlighted. A full quality dossier is required for biosimilars. This should be supplemented by the demonstration of comparability (the exercise that will provide the two products have a similar profile in terms of quality safety efficacy).

\section{Non-clinical studies}

Before initiating non-clinical studies, results from the quality comparability studies including physiochemical and biological characterization studies should be reviewed from the point of view of the potential impact on efficacy and safety.

\section{Clinical studies}

The clinical comparability exercises is a stepwise approach that should ideally start with the pharmacokinetics and pharmacodynamics studies 
followed by the efficacy and clinical safety and clinical efficacy trials will be required, the clinical studies and nature of a biosimilar trial are likely to depend on the product class. All the clinical studies should address the immunogenicity characteristics.

\section{REQUIREMENTS FOR CONDUCTING CLINICAL TRIAL IN INDIA}

For new drugs discovered in India, Phase 1 clinical trials may be conducted in India or outside India and submitted as per the requirements. However, for new drugs discovered in countries other than India, first in human studies cannot be conducted in India but in some cases repeat dose studies can be conducted subjected to regulatory approvals. The Phase 1 data need to be submitted along with the application for conduct of Phase 2 trials, and subsequently, for Phase 3 trials. Phase 3 trials are required to be conducted in India before permission to market the drug in India is granted. Application for permission to initiate specific phase of clinical trial should be submitted in Form 44 and Appendix 1. A clinical trail application utilizes Form 44, accompanied by documents pertaining to chemical and pharmaceutical information, animal pharmacology, toxicology data, and clinical pharmacology data. Other trial-related documents that must be submitted for approval includes the Investigator's Brochure, trail protocol, case report form, informed consent document, investigator's undertaking. In addition, the trial's regulatory status of the trial in other countries must be reported. The requirements in respect of chemistry and Pharmaceuticals information have been elaborated separately for biological products while other requirements for conduct of clinical trial and other requirements remain the same as per Schedule $\mathrm{Y}$ of Drugs and Cosmetics Rules 1945. A checklist has been published by the CDSCO office for the conductance of Phase 1,2, and 3 clinical trials as given. The anticipated timeline for the approval of conduct of the study is around 8-12 if direct approval is granted. But if it is a new drug/First in human trials, the applications are referred to the IND Committee which would take anywhere from 12 to 24 weeks to give their opinion, based on this opinion the DCGI office may approve (with or without some changes to the protocol) or seek clarifications or decline approval.

Import license/Test license in Form 11 is obtained from DCGI whenever the clinical study drugs, biological samples, diagnostics kits are to be imported for the purpose of tests and analysis during the conduct of clinical trials/BA-BE studies. The documents to be submitted for the import License include:

Application with form 12

- The purpose of import and detailed utilization indicating nature of tests and quantity required for each test.

- Authorization letter from the sponsor for the import license

- Justification and utilization breakup

The anticipated timeline for the DCGI approval would be 4-6 weeks. Once the license is issued, it is valid for multiple shipments for 1 year or the till the quantities approved are exhausted whichever is earlier. After the expiry of import kicense, new application needs to be submitted for DCGI approval. When the biological samples (e.g., blood, serum, plasma, and urine) are required to be collected during the clinical trial and exported out of the country for analysis, a "No Objection Certificate" (NOC) has to be obtained from DCGI. The application is applied toails, the DCGI with the following information like type of sample, shipment details, address of the laboratory where the analysis to be conducted and purpose of the export of biological sample. The export NOC could also be used applied parallel with the clinical study approval (Fig. 2).

\section{INDIAN GUIDELINES}

The New India Guidelines "Draft Guidelines on Similar Biologics: Regulatory Requirements for Marketing Authorization in India," were announced in June 2012, by DBT. The Indian Guidelines on similar biologics address the premarketing and post marketing regulatory requirement (i.e., "comparability exercises"), and also address the requirements related to manufacturing process and quality control. As such these Indian guidelines on similar biologics are comparable in many respects to biosimilar guidelines of USA and EU. India has adopted a "sequential approach" (like "stepwise approach" US and EU) to market biosimilar products [12]. The Review Committee on genetic manipulation of the Genetic Engineering Approval Committee with the permission of DCGI, approves clinical trials to be conducted in India related to biosimilar therapeutic products. The biosimilar has to demonstrate comparableof clinical studies, viz., Pharmacokinetics and toxicology. (Safety pharmacology, reproduction toxicology, mutagenicity, and carcinogenicity) and clinical studies (efficacy and tolerability for each indication) before it gets approval for all indication of the reference medicine [13]

Biosimilars in India [14] consist primarily of vaccine, monoclonal antibodies, recombinant proteins and diagnostics, insulin (wosulin, insugen, recosulin), erythropoietin (hemax, epofer, wepox, ceriton, epofit), hepatitis B vaccine (Shanvac B, Revac B, Enivac B, Biovac B, Genevac B, Bevac), granulocyte colony stimulating factor (GCSFGrastim, Neukine), streptokinase (indikinase, shankinase, STPase), interferon alpha 2B (shanferon), Rituxinab (MAb), epidermal growth factor receptor (anti-EGFR) MAb-(reditux, bioMABEGFR). Status of similar biologics in India is elaborated in Table 2 [15-17].

There are about 100 biopharmaceutical companies actively involved in research and development, manufacturing and marketing of biosimilar therapeutic products in India. There were 14 therapeutic drugs (similar biologics) available in 50 brands in 2005; The number has increased to 20 therapeutic drugs in 250 brands in 2011. Biosimilar therapeutic products include insulin, erythropoietin, chorionic gonadotropin, streptokinase, interferon, and heparin. The growing biosimilars market offers huge potential for companies involved in manufacturing, research, and development [18].

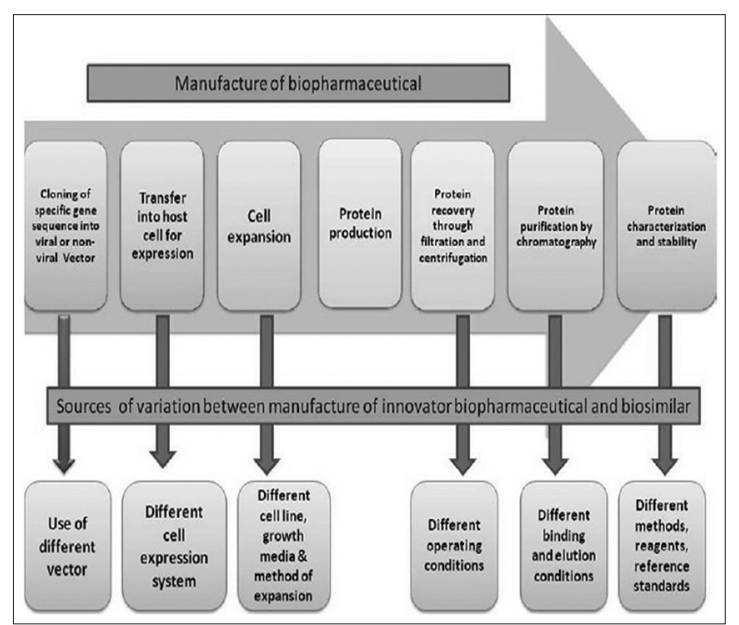

Fig. 2: Manufacture of biopharmaceutical and source variation between manufacturer of innovator biopharmaceutical and biosimilar

Table 1: Format of dossier-module of common technical document

\begin{tabular}{lll}
\hline 1 & Administrative information & Normal requirements \\
2 & Quality (chemical, pharmaceutical and biological information & Full+comparability exercise \\
3 & Non-clinical study reports & Reduced++comparability exercise \\
4 & Clinical study reports & Reduced++comparability exercise \\
\hline
\end{tabular}


Table 2: Status of similar biologics in India [15-17]

\begin{tabular}{|c|c|c|c|}
\hline Company name & Product name & Active substance & India launch year \\
\hline Biocon & Basalog & Insulin glargine & 2009 \\
\hline Wockhardt & Biovac & Hepatitis b & 2000 \\
\hline Wockhardt & Wepox & Epoetin alfa & March 2001 \\
\hline Wockhardt & Wosulin & Human insulin & 13 August 2003 \\
\hline $\mathrm{Sb} /$ merieux alliance & Shanferon & Interferon alpha 2 & April 2002 \\
\hline $\mathrm{Sb} /$ merieux alliance & Shanpoietin & Erythropoietin & January 2005 \\
\hline $\mathrm{Sb} /$ merieux alliance & Shankinase & Streptokinase & June 2004 \\
\hline Reliance life sciences & Relipoietin & Epotein alfa & 2008 \\
\hline
\end{tabular}

After completion of the clinical study detailed reports should be submitted to DCGI. The dossier should be in CTD format that must be approved by DCGI. The DCGI recommends license for manufacturing after inspection of the facility. After approval of biosimilar for the market, post-marketing surveillance is essential for at least 4 months and pharmacovigilance monitoring throughout the study. In addition to that periodic safety update report should be reported to DCGI in every 6 months for first 2 years. Any change in process must to be authorized by DCGI [19].

\section{CONCLUSION}

Biosimilars are copy drugs similar to biological drugs that have already been authorized (the biological reference medicine), hence similar but not identical. Indian guidelines define a "similar biologics" as a biological product/drug produced by genetic engineering techniques and claimed to be "similar" in terms of safety, efficacy, and quality to a reference biologics, which has been authorized by DCGI for safe use in India. The active substance of biosimilar medicine is similar to one of the biological reference medicine and used in general at the same dosage to treat the same disease. Biosimilars are entity based (including product process), regulatory-based (under an abbreviated testing), and market-based (same manufacturers, different trade names).

\section{ACKNOWLEDGMENT}

Authors want to acknowledge the management of SRM University.

\section{REFERENCES}

1. Schellekens H. Biosimilar therapeutics-what do we need to consider? NDT Plus 2009;2(Suppl 1):i27-36.

2. Sekhon BS, Saluja V. Biosimilars: An overview. Biosimilars. 2011;1:1-11.

3. Leader B, Baca QJ, Golan DE. Protein therapeutics: A summary and pharmacological classification. Nat Rev Drug Discov 2008;7(1):21-39.

4. Revers, L, Furczon E. An introduction to biologics and biosimilars. Part II: Subsequent entry biologics: Biosame or biodifferent? Can Pharm J 2010;143:184-91.

5. Scitable by nature education. Recombinant DNA technology. Available from: $\quad$ http://www.nature.com/scitable/definition/recombinantdnatechnology-dna-cloning-gene-cloning. [Last accessed on 2014 Oct 10]

6. Revers, L, Furczon E. An introduction to biologics and biosimilars: Part I: Biologics: What are they and where do they come from? Can Pharm J 2010;143:134-9.

7. Zelenetz AD, Ahmed I, Braud EL, Cross JD, Davenport-Ennis N, Dickinson BD, et al. NCCN biosimilars white paper: Regulatory, scientific, and patient safety perspectives. J Natl Compr Canc Netw 2011;9 Suppl 4:S1-21.

8. Goldsmith D, Kuhlmann M, Covic A. Through the looking glass: The protein science of biosimilars. Clin Exp Nephrol 2007;11(3):191-5.

9. Simoens, S. Biosimilar medicines and cost-effectiveness. Clinicoecon Outcomes Res. 2011;3:29-36.

10. Schneider CK. Biosimilars in rheumatology: The wind of change. Ann Rheum Dis 2013;72(3):315-8.

11. Stork WR. Therapeutic monoclonal antibodies- past, present, future. In: An Z, editor. Therapeutic Monoclonal Antibodies-from Bench to Clinic. New York: John Wiley \& Sons; 2009. p. 4-50.

12. India Releases Draft "Similar Biologi" Mol, Belgium: Pro Pharma Communications International. GaBI Online-Generics and Biosimilars Nitiative. Available from: http://www.gabionline.net/Guidelines/ India-releases-draft-similar-biologic-guidelines. [Last accessed on 2013 Jul 16].

13. Declerck P. Biologicals and biosimilars: A review of the science and its implications. Generics Biosimilars Initiat J (GaBI J) 2012;1(1):13-6.

14. OPPI position paper on "biosimilar" in India. Available from: http://www.indiaoppi.com/oppibiosimilars.pdf. [Last accessed on $2013 \mathrm{Jul} 16]$.

15. Jayaraman K. India's Cipla sets sights on Avastin, Herceptin and Enbrel. Nat Biotechnol 2010;28(9):883-4.

16. Mody R, Goradia V, Gupta D. How similar are biosimilars in India? Pharmafocus Asia. Ochre media. Available from: http://www. pharmafocusasia.com/research_development/blind-comparative-study. html. [Last accessed on $2013 \mathrm{Ju} l 18]$.

17. Som N. India on biologics trail. Biospectrum. 2012. Available from: $\mathrm{http} / / / \mathrm{www} \cdot$ biospectrumindia.com/biospecindia/news/155886/indiabiologics-trail. [Last accessed on $2013 \mathrm{Jul} 20]$.

18. Rathore A. Development and commercialization of biosimilars in India. BioPharm Int 2011;24:36-40.

19. Misra M. Biosimilars: Current perspectives and future implications. Indian J Pharmacol 2012;44(1):12-4. 